\title{
Traffic Noise Propagating from Vibration of Railway Wagon
}

\author{
Shao-Yi Hsia ${ }^{1}$ and Yu-Tuan Chou ${ }^{2}$ \\ ${ }^{1}$ Department of Mechanical and Automation Engineering, Kao Yuan University, Kaohsiung 821, Taiwan \\ ${ }^{2}$ Department of Applied Geoinformatics, Chia Nan University of Pharmacy and Science, Tainan City 717, Taiwan
}

Correspondence should be addressed to Shao-Yi Hsia; syhsia@cc.kyu.edu.tw

Received 15 September 2013; Accepted 22 October 2013

Academic Editor: Teen-Hang Meen

Copyright (c) 2013 S.-Y. Hsia and Y.-T. Chou. This is an open access article distributed under the Creative Commons Attribution License, which permits unrestricted use, distribution, and reproduction in any medium, provided the original work is properly cited.

Traffic noise has become a serious environmental hazard as more cars are purchased and driven. To help objectively and subjectively reduce perceived noise load, methods to analyze traffic noise offer an important means of creating a design to reduce noise output from main sources and transmission routes. Acoustic analysis using BEASY and dynamic analysis using ANSYS are conducted to forecast noise at a distance of $15 \mathrm{~m}$ from a railway wagon travelling at $100 \mathrm{~km} / \mathrm{h}$. This noise is based on structural vibration only and it excludes other noise sources from the railway wagon. The simulation results demonstrate that the overall noise at $15 \mathrm{~m}$ from a railway wagon car is $85.1 \mathrm{~dB}(\mathrm{~L})$ from linear energy weighting calculation and $72.9 \mathrm{~dB}(\mathrm{~A})$ from the A-weighting calculation. In this study, noise level propagating from vibration of the railway wagon is measured or calculated using A-weighting filter to simulate the frequency response of the human ear. The study results can be useful to factories, companies, or organizations and can provide an important resource and help reduce traffic noise. This can be achieved by predetermining the test location and structure configuration and adapting local planning and thus preventing excessive traffic noise in residential areas.

\section{Introduction}

Noise pollution is one of the negative issues of environmental pollution in metropolitan areas and is one of the most detrimental agents. It is estimated that over half of the world's population is exposed to unacceptable noise levels. In general, the major noise source is from road transportation followed by aircraft and railway noise; therefore many countries have regulations and laws to control noise emission limits for vehicles in order to reduce traffic noise. In recent years in some countries, new restricted rules were enacted for controlling city road traffic noise. The recognition of road traffic noise as one of the main sources of environmental pollution led to designed models and devices that enable us to predict traffic noise levels. Several models have been developed from fundamental variables such as the traffic flow, speed of vehicles, and sound emission levels using regression analysis of experimental data [1-4].

Facing the worsening pollution caused by every day traffic, the EU has set a goal to solve this problem and has been trying different ways to lower the traffic noise to a healthier level for the people who are regularly affected by the long-term average noise levels in its 6th Environmental Action Program [5]. Unpleasant, frequent, and long-lasting traffic noise can cause many health issues psychologically and physically, to name a few, such as fear, uncertainty, mild anger, and even hearing loss. In densely populated areas, traffic is the single most important source of noise annoyance $[6,7]$. Traffic noise prediction models are required as aids in designing highways and various types of roads and often are also very helpful to reduce the existing unbearable noise conditions. Traffic noise prediction models in the 1950s and 1960s were designed to predict a single vehicle sound pressure level $(L p)$ at the roadside. These models were based on constant speed experiments, the predicted levels then being expressed as functions of speed and with zero acceleration.

This report highlights the scale and scope of the traffic noise problem, which focuses on road and rail transport, for example, a wagon traveling at $100 \mathrm{~km} /$ hour. At the beginning, the frequency response should be derived from the time history of the measured velocity for the wagon. Then, a boundary element method was used to simulate the noise distribution of the wagon. The objective of the analysis was to predict the noise level at $15 \mathrm{~m}$ away from the wagon when it 
is passing by at $100 \mathrm{~km} /$ hour and when it is empty. In conclusion, a number of recommendations for action were given and recorded.

\section{Sound Field Simulation for Railway Wagon}

In this simulation, the sound source intensity and propagation are separated for analysis using the Finite Element (FEM) and Boundary Element (BEM) methods, respectively. Noise analysis is examined using two commercial softwares. The sound source is obtained from ANSYS simulation. The increasing sound is calculated using BEASY simulation.

2.1. Sound Source Identification. When analyzing acoustic simulation, the coupling of fluid and a structure is generally taken into account. Meanwhile, the dynamic equation for a structure and Navier-Stokes equation for flow are also calculated and analyzed. Assuming fluid being compressible and nonviscous, average velocity being zero, and average pressure and density being uniform, the continuous equations could be simplified as an acoustic wave equation in the kinematic equation for fluid as follows:

$$
\frac{1}{c^{2}} \frac{\partial^{2} p}{\delta t^{2}}-\nabla^{2} p=0
$$

where $c$ is the velocity of sound of fluid, $p$ is the acoustic pressure, and $t$ is the time. In consideration of the harmonic change of acoustic pressure with frequency, it is assumed that

$$
p=\bar{p} e^{j \omega t}
$$

where $\bar{p}$ stands for the amplitude of acoustic pressure and $\omega$ stands for the angular frequency. Equation (1) could be simplified as Helmholtz equation, as shown below:

$$
\frac{\omega^{2}}{c^{2}} \bar{p}+\nabla^{2} \bar{p}=0 .
$$

Once the vibration velocity of structure is known, the acoustic pressure can be obtained using a mathematical transformation. For plane acoustic waves, the specific acoustic impendence $Z$ is simply a function of the fluid properties. Consequently, the relation between the acoustic velocity $u$ and acoustic pressure $p$ is represented by

$$
p=Z u=\rho c u
$$

where $\rho$ represents the mass density.

2.2. Boundary Element Method for Acoustic Simulation. When considering the noise source, the linear wave equation form (4) propagation through an elastic medium governs can be rewritten as

$$
\nabla^{2} u=\frac{1}{c^{2}} \frac{\partial^{2} u}{\partial t^{2}}+b
$$

where $b(x, t)$ is the noise source.

Similar to (2), (5) can be expressed as time harmonic and can be transferred to the modified Helmholtz equation as follows:

$$
\nabla^{2} u+k^{2} u=b
$$

where $k=\omega / c$ denotes the wave number. Equation (6) at the specified angular frequency $\omega$ can be expressed in matrix form as [8]

$$
H P=G V+B
$$

where $H$ and $G$ are frequency dependent coefficients, $P$ and $V$ are the pressure and velocity, and $B$ denotes a body force vector.

\section{Analysis Model}

People react differently to noise from a passing train versus noise from road traffic. The passage of a train has a defined beginning and end within a specified duration. On the other hand, urban traffic noise is more or less continuous, particularly at rush hour and in a busy city. Moreover, railway noise typically occurs some distance from human habitation, and since the passage of each train lasts only a short period it does not normally carry a risk of hearing damage, since the ambient noise level is restored. Railway noise also produces a different physical response to other traffic noise sources. Understanding the nature of railway noise requires understanding railway bed construction, including its tie-and-ballast design. The ties generally comprise treated wood strips, while the weight/base is crushed rock piled and placed beneath the ties on drained and graded ground. The ties distribute the weight from the tracks, and several noise sources were identified to be associated with the passage of a train like the following: (a) wheel/rail interaction, (b) car coupler contact, and (c) vibration of structural parts of the railroad car. The cause of wheelrail noise is generally thought to be wheel and rail structural vibrations excited by a combination of the wheel and rail surface roughness. On the other hand, vibration of structural parts refers to the transport structures to be subjected to loads that vary in both time and space. In this research, the vibration of the structural parts of the car, for example, the bogie pivots, is measured and shown to be the main cause of noise. Figure 1 shows the geometry and the initial FE mesh. A flowchart about the analysis process is shown in Figure 2. The first step in measuring the noise level at $15 \mathrm{~m}$ is to locate the sound source of the car. According to the new LW3 profiles over the track factored to just meet QR track category 6, the velocity histories of train's pivot points are calculated for $100 \mathrm{~km} / \mathrm{h}$ railway wagon speed and shown in Figure 3. Consequently, the noise history record of the bogie pivots stimulated in this study are listed as follows:

(a) time in seconds and output interval 1/20,000th sec,

(b) lateral velocity in body over the leading bogie pivot in $\mathrm{m} / \mathrm{s}$,

(c) lateral velocity in body over the trailing bogie pivot in $\mathrm{m} / \mathrm{s}$, 


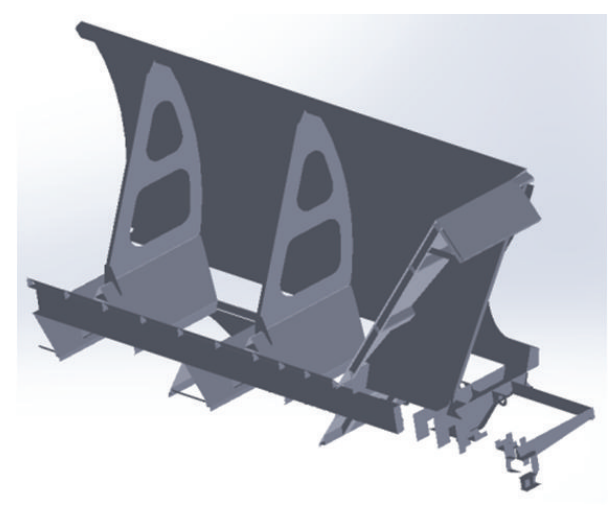

(a)

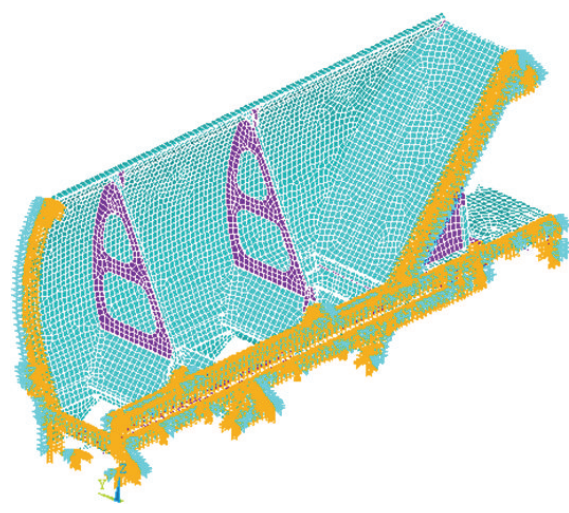

(b)

FIGURE 1: 1/4 configuration of the railway wagon.

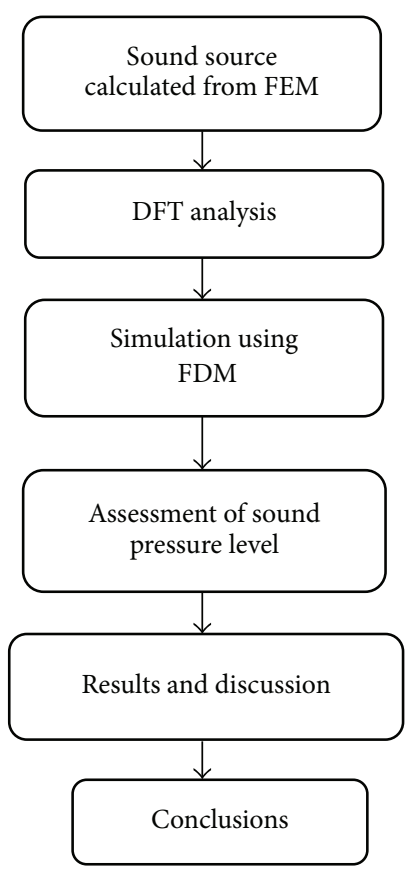

FIGURE 2: Flowchart of analysis process.

(d) vertical velocity in body over the leading bogie pivot in $\mathrm{m} / \mathrm{s}$,

(e) vertical velocity in body over the trailing bogie pivot in $\mathrm{m} / \mathrm{s}$.

This study considers velocity response of four locations, namely, the lateral and vertical velocities of the leading and trailing pivots. The time interval for each point is 0.0005 seconds and 65,536 points are shown. Regarding sound transmission, the frequency response should be significant based on the time history of the velocity. Furthermore, the Discrete Fourier Transform (DFT) is applied using MATLAB software to yield the velocity responses.

Since the time interval is 0.0005 seconds, the calculated frequency can be obtained ranging from 0 to $1,000 \mathrm{~Hz}$.

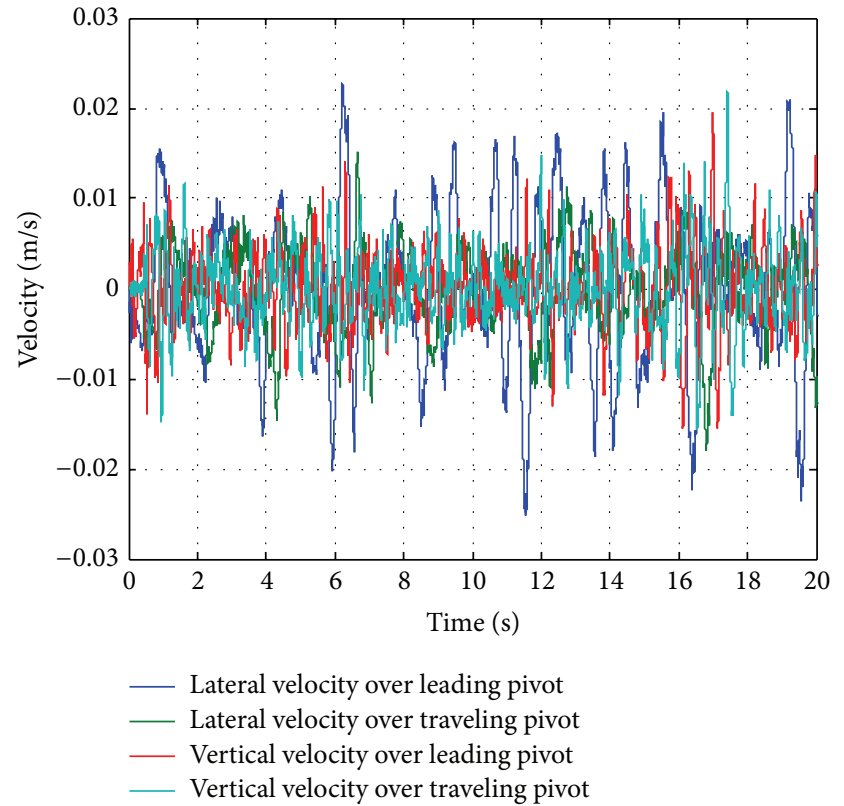

FIGURE 3: Velocity histories of train's pivot points.

The unstudied information does not have adequate data resolution to obtain a higher frequency response. Acoustic analysis reveals the sound frequency is spread across a wide range, meaning it is unnecessary to analyze each frequency. The $1 / 3$ octave frequency thus is frequently used to derive the transmission characteristics. Therefore, the velocity excitations listed in Table 1 were applied to the bogie pivot points.

Once the vibration velocity of structure is known, the acoustic pressure can be obtained using a mathematical transformation. For plane acoustic waves, the specific acoustic impendence $Z$ is simply a function of the fluid properties. Consequently, the relation between the acoustic velocity $u$ and acoustic pressure $p$ is represented by (4). Various qualities are used in acoustics, including acoustic pressure and intensity. For example, an undamaged human ear can detect 
TABLE 1: Lateral and vertical velocities at 1/3 octave over leading and trailing pivot.

\begin{tabular}{lcccc}
\hline Frequency $(\mathrm{Hz})$ & Lat.vel.over ldg.pivot $(\mathrm{m} / \mathrm{s})$ & Lat.vel.over tlg.pivot $(\mathrm{m} / \mathrm{s})$ & Vert.vel.over ldg.pivot (m/s) & Vert.vel.over tlg.pivot (m/s) \\
\hline 20 & $7.62 E-04$ & $3.46 E-05$ & $6.36 E-04$ & $3.43 E-04$ \\
25 & $1.18 E-04$ & $2.11 E-05$ & $1.42 E-04$ & $4.96 E-05$ \\
31.5 & $1.92 E-04$ & $2.45 E-06$ & $1.85 E-04$ & $3.35 E-05$ \\
40 & $7.51 E-05$ & $3.80 E-06$ & $4.29 E-05$ & $4.28 E-06$ \\
50 & $2.69 E-05$ & $5.05 E-06$ & $5.70 E-05$ & $1.46 E-05$ \\
63 & $3.82 E-05$ & $1.76 E-06$ & $4.88 E-05$ & $1.15 E-05$ \\
80 & $1.46 E-05$ & $1.75 E-06$ & $1.91 E-05$ & $4.19 E-06$ \\
100 & $1.05 E-05$ & $7.02 E-07$ & $7.18 E-06$ & $1.27 E-06$ \\
125 & $5.18 E-06$ & $6.90 E-07$ & $4.34 E-06$ & $8.14 E-07$ \\
160 & $3.96 E-06$ & $2.85 E-07$ & $1.18 E-06$ & $1.62 E-08$ \\
200 & $2.46 E-06$ & $2.02 E-07$ & $5.73 E-07$ & $7.91 E-08$ \\
250 & $1.58 E-06$ & $1.30 E-07$ & $4.25 E-07$ & $4.33 E-08$ \\
315 & $9.64 E-07$ & $8.71 E-08$ & $2.57 E-07$ & $1.51 E-08$ \\
400 & $6.26 E-07$ & $5.48 E-08$ & $1.66 E-07$ & $1.24 E-08$ \\
500 & $4.15 E-07$ & $3.62 E-08$ & $1.04 E-07$ & $5.95 E-09$ \\
625 & $2.86 E-07$ & $2.45 E-08$ & $6.57 E-08$ & $5.04 E-09$ \\
800 & $1.97 E-07$ & $1.66 E-08$ & $4.88 E-08$ & $3.47 E-09$ \\
1,000 & $1.46 E-07$ & $1.28 E-08$ & $3.42 E-08$ & $2.07 E-09$ \\
\hline
\end{tabular}

TABLE 2: Lateral and vertical sound levels at $1 / 3$ octave over leading and trailing pivot.

\begin{tabular}{lcccc}
\hline Frequency $(\mathrm{Hz})$ & Lat.pres.over ldg.pivot $(\mathrm{dB})$ & Lat.pres.over tlg.pivot (dB) & Vert.pres.over ldg.pivot (dB) & Vert.pres.over tlg.pivot (dB) \\
\hline 20 & 105.7 & 79.0 & 104.2 & 98.9 \\
25 & 92.1 & 76.8 & 93.2 & 84.2 \\
31.5 & 97.8 & 60.3 & 97.4 & 87.4 \\
40 & 91.7 & 66.0 & 91.3 & 68.0 \\
50 & 84.8 & 70.2 & 91.9 & 79.5 \\
63 & 89.8 & 63.0 & 85.9 & 79.4 \\
80 & 83.6 & 64.9 & 79.3 & 72.6 \\
100 & 82.6 & 59.1 & 76.8 & 64.1 \\
125 & 78.4 & 60.9 & 67.7 & 62.3 \\
160 & 78.2 & 55.3 & 63.4 & 30.4 \\
200 & 76.0 & 54.3 & 62.7 & 46.1 \\
250 & 74.1 & 52.4 & 60.3 & 42.8 \\
315 & 71.8 & 50.9 & 58.6 & 35.7 \\
400 & 70.1 & 49.0 & 56.4 & 36.1 \\
500 & 68.5 & 47.3 & 54.4 & 31.6 \\
625 & 67.2 & 45.9 & 54.0 & 32.1 \\
800 & 66.1 & 44.6 & 52.8 & 31.0 \\
1,000 & 65.4 & 44.3 & & 28.5 \\
\hline
\end{tabular}

sounds with an acoustic pressure as low as $20 \mu \mathrm{Pa}$ and can withstand sounds with a sound pressure as high as $20 \mathrm{~Pa}$ for a few minutes. Additionally, it was found that the response of the human ear to sound depends more on the ratio of the intensity of one sound to another, rather than on the difference in the intensity. Consequently, this analysis uses a logarithmic sound pressure level (dB). Combining (4) and the concept of relation between sound pressure and acoustic velocity can obtain the acoustic sources of the bogie pivot points, which are listed in Table 2. In this table, $\rho c$ is $408 \mathrm{~Pa} \cdot \mathrm{s} / \mathrm{m}$ due to the air characteristic.
In rail transport design of structures intended to mitigate noise, it is frequently necessary to estimate the sound pressure level produced from the noise source of the wagon. This investigation examined the BEASY acoustic software, which can be used to predict noise emission from the sound field around a moving railway wagon. Generally, it is essential to predict not only overall noise level, but also the noise spectrum or sound pressure level in each octave band. Knowledge of the sound pressure level spectrum enables prediction of the A-weight sound level, which is important in determining compliance with noise regulations. 


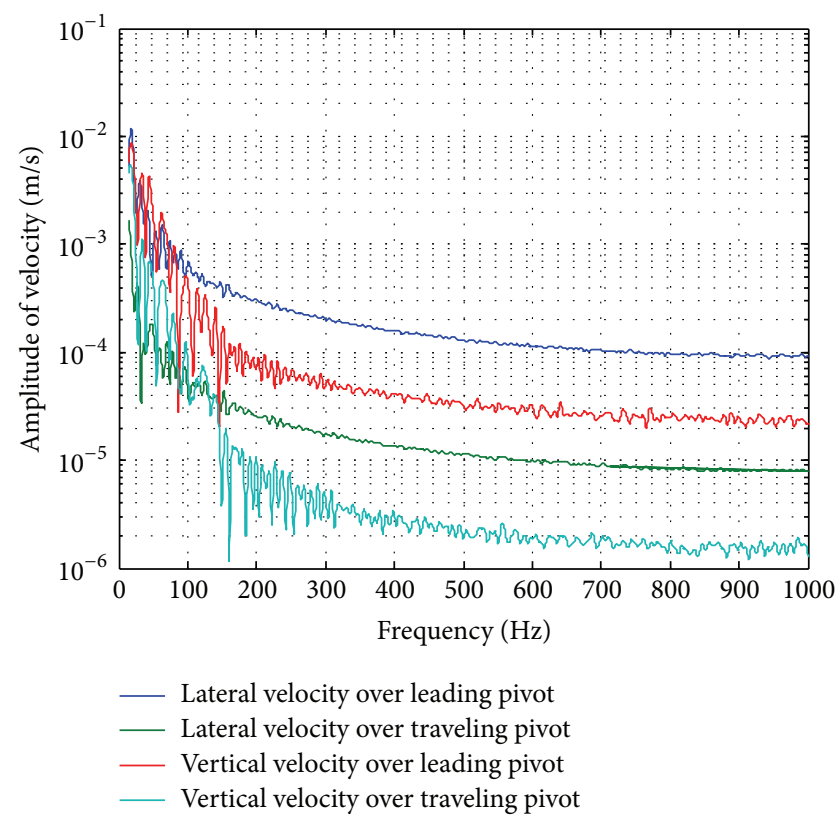

FIGURE 4: Vibration amplitude of velocity versus frequency for four wheels.

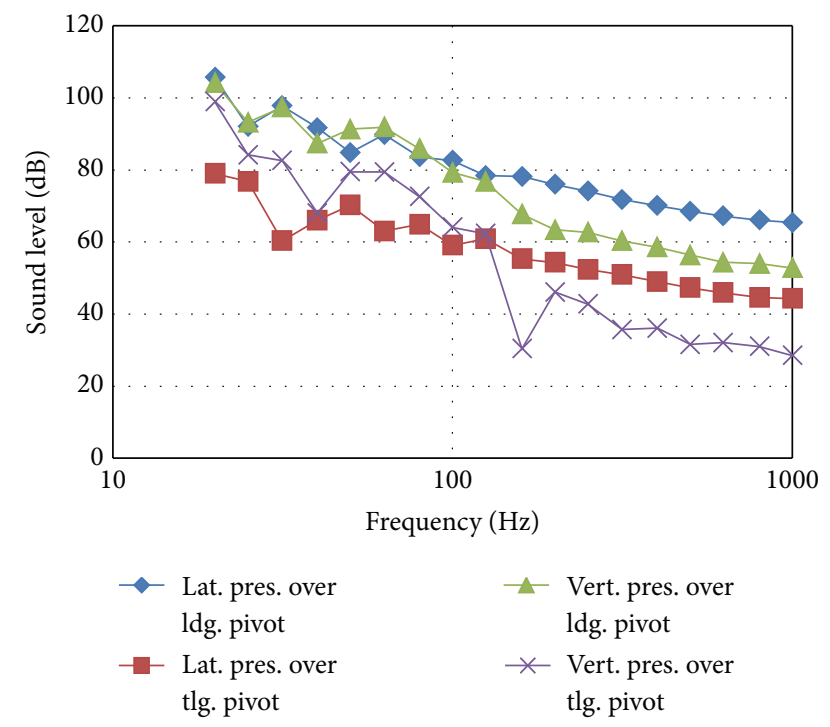

FIGURE 5: Sound source of the train's pivot points at $1 / 3$ octave frequency.

\section{Results and Discussion}

The vibration velocity at $1 / 3$ octave frequency of the car over leading and trailing pivots is analyzed by applying MATLAB software as shown in Table 1. Figure 3 shows detailed information on the vibration data, and Figure 4 shows the FFT result. Structural vibration influences the sound source on the car. The pressure level of the sound source is calculated by (4) and can be converted to $\mathrm{dB}$ level at 1/3 octave frequency, as listed in Table 2 . Table 2 clearly shows that the maximum value of the sound source is $105.7 \mathrm{~dB}$ at $20 \mathrm{~Hz}$ on the lateral

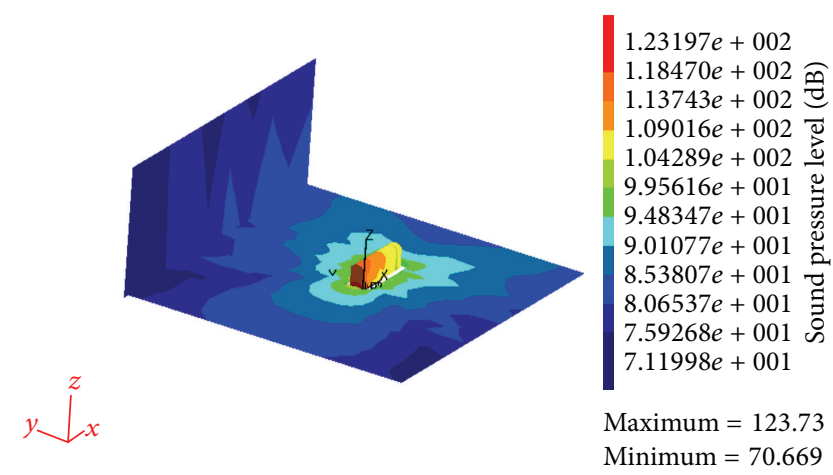

Figure 6: Lateral pressure of the leading pivot at $100 \mathrm{~Hz}$ from distance of $15 \mathrm{~m}$.

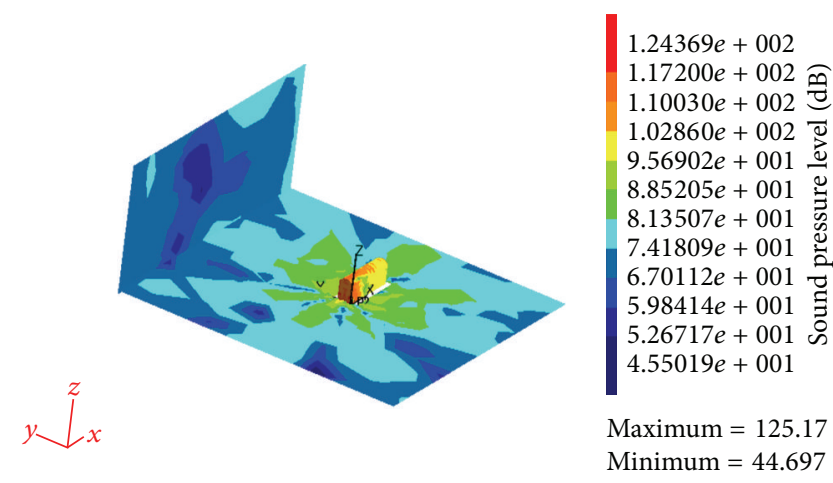

Figure 7: Lateral pressure of the leading pivot at $500 \mathrm{~Hz}$ from distance of $15 \mathrm{~m}$.

leading pivot. The values of the sound source on the leading pivots exceed those on the trailing pivots. Figure 5 shows the spectrum across $1 / 3$ octave of the sound source for various cases. The figures show that the lowest frequencies are always maximized for the four cases and then decay along the higher frequencies. The frequencies also differ most during 31.5 to $50 \mathrm{~Hz}$. The profile of a car is modeled using BEASY software and the sound source from Table 2 is inserted on the leading and trailing pivots to reproduce the sound field. For acoustic analysis, the sound field of the car is indicated on the attachment, and Table 3 lists the predicted noise level at $15 \mathrm{~m}$. For further information on the acoustic distribution around the car, three simulations of the lateral pressure of the leading pivot at $100 \mathrm{~Hz}, 500 \mathrm{~Hz}$, and $1000 \mathrm{~Hz}$, as listed in Table 3, are shown in Figures 6, 7, and 8. The red color in the figures represents the high sound pressure level distribution, and the blue area denotes the low sound pressure level. The sound pressure level is shown in $\mathrm{dB}$ on the bar chart beside the sound field distribution profile. These figures also showed that the red color is concentrated in the center of the car. This phenomenon demonstrates that high level sound pressure surrounds the car. The results in Figures 6-8 also clearly demonstrate that the noise gradually reduces with distance. This means that the sound pressure depends on distance from the source. Some further interesting facts regarding the higher frequency, for example, $1000 \mathrm{~Hz}$, are shown in 
TABLE 3: Sound pressure levels at 1/3 octave over leading and trailing pivot at $15 \mathrm{~m}$.

\begin{tabular}{|c|c|c|c|c|c|c|}
\hline $\begin{array}{l}\text { Frequency } \\
(\mathrm{Hz})\end{array}$ & $\begin{array}{c}\text { Lat.pres.over } \\
\text { ldg.pivot }(15 \mathrm{~m}, \mathrm{~dB})\end{array}$ & $\begin{array}{c}\text { Lat.pres.over } \\
\text { ldg.pivot }(15 \mathrm{~m}, \mathrm{~dB})\end{array}$ & $\begin{array}{c}\text { Vert.pres.over } \\
\text { ldg.pivot }(15 \mathrm{~m}, \mathrm{~dB})\end{array}$ & $\begin{array}{l}\text { Vert.pres.over } \\
\text { tlg.pivot }(15 \mathrm{~m}, \mathrm{~dB})\end{array}$ & $\begin{array}{c}\text { Combined } \\
\text { noise level }(15 \mathrm{~m}, \mathrm{~dB})\end{array}$ & $\begin{array}{c}\text { Combined } \\
\text { noise level (15 m, } \\
\text { dBA) }\end{array}$ \\
\hline 20 & 82.1 & 55.3 & 80.6 & 75.2 & 84.2 & 33.7 \\
\hline 25 & 70.0 & 54.7 & 71.1 & 62.2 & 73.5 & 28.8 \\
\hline 31.5 & 75.3 & 58.4 & 75.5 & 60.7 & 78.5 & 39.1 \\
\hline 40 & 69.8 & 44.0 & 65.4 & 46.0 & 71.1 & 36.5 \\
\hline 50 & 64.2 & 69.6 & 70.7 & 58.9 & 73.7 & 43.5 \\
\hline 63 & 69.3 & 42.9 & 71.8 & 59.2 & 73.7 & 47.5 \\
\hline 80 & 65.5 & 47.2 & 68.1 & 54.8 & 70.0 & 47.5 \\
\hline 100 & 69.7 & 46.2 & 66.4 & 51.3 & 71.3 & 52.2 \\
\hline 125 & 72.0 & 54.5 & 70.4 & 55.9 & 74.3 & 58.2 \\
\hline 160 & 62.0 & 39.1 & 51.5 & 14.2 & 62.4 & 49.0 \\
\hline 200 & 67.9 & 46.2 & 55.3 & 38.1 & 67.9 & 57.0 \\
\hline 250 & 64.2 & 42.5 & 52.8 & 32.9 & 64.2 & 55.6 \\
\hline 315 & 56.6 & 36.3 & 45.7 & 21.1 & 56.7 & 50.1 \\
\hline 400 & 75.0 & 53.9 & 63.5 & 39.6 & 75.1 & 70.3 \\
\hline 500 & 61.8 & 40.6 & 47.7 & 22.7 & 61.8 & 58.6 \\
\hline 625 & 57.1 & 35.7 & 49.8 & 19.9 & 57.8 & 55.9 \\
\hline 800 & 70.2 & 48.8 & 58.1 & 35.2 & 70.2 & 69.4 \\
\hline 1000 & 60.5 & 39.4 & 47.9 & 23.5 & 60.5 & 60.5 \\
\hline \multicolumn{5}{|c|}{ Overall noise level } & 85.1 & 72.9 \\
\hline
\end{tabular}

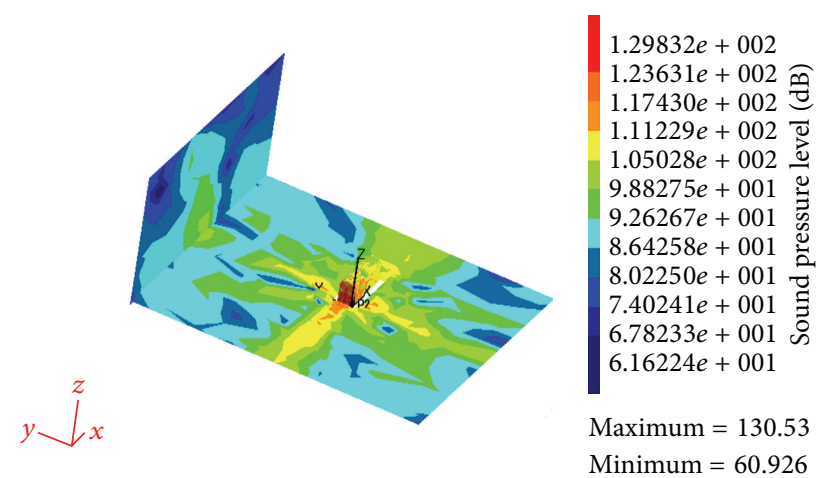

FIGURE 8: Lateral pressure of the leading pivot at $1000 \mathrm{~Hz}$ from distance of $15 \mathrm{~m}$.

Figure 8. This figure shows the energy variation outside the car compared with Figures 6 and 7. This phenomenon means that the small wavelength radiates energy more easily at high frequency.

Figure 9 illustrates the noise level spectrum across 1/3 octave for various cases using the simulation results listed in Table 3. When the observer is located at a distance that exceeds one-third of the car length, the car appears closer as a point source and the radiation generates a spherical wave. Consequently, the acoustic pressure varies inversely with distance from the car, since the acoustic power is constant given zero energy dissipation. The acoustic power thus becomes spread over a larger area as the sound wave departs the

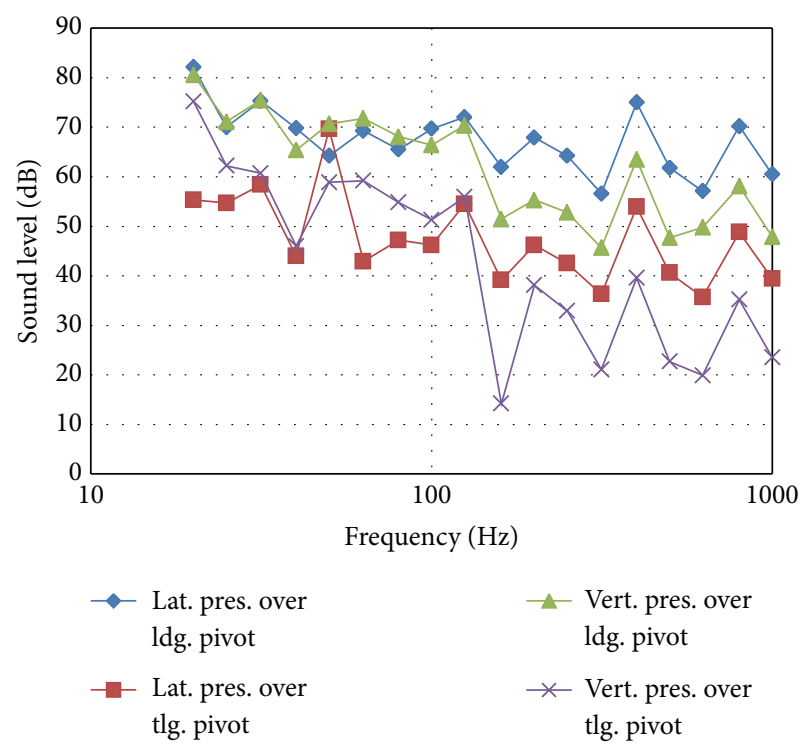

FIGURE 9: Noise level of the train's pivot points from the distance of $15 \mathrm{~m}$.

source, causing an inverse decrease in the acoustic intensity proportionally with the square of the calculated distance from the observer to the car. Most frequencies decrease their acoustical pressures when comparing Figure 5. The acoustical field illustrated in the figure also indicates higher noise levels at $500 \mathrm{~Hz}$ and $1000 \mathrm{~Hz}$. 


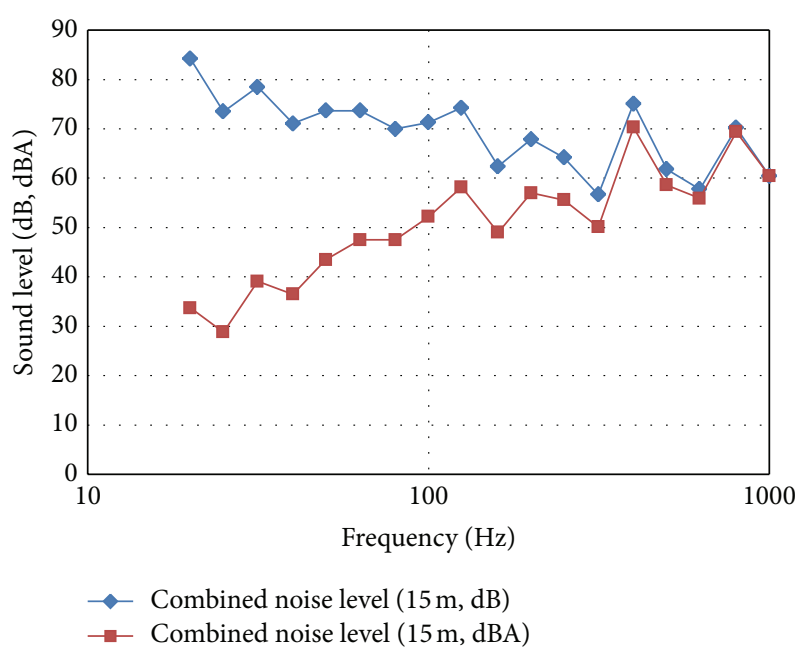

FIGURE 10: The 1/3 octave spectrums of linear and A-weighting noise level at $15 \mathrm{~m}$.

Table 3 reveals that the combined noise level is $85.1 \mathrm{~dB}(\mathrm{~L})$ from the linear weighting of energy and $72.9 \mathrm{~dB}(\mathrm{~A})$ from the A-weighting filtered noise. $\mathrm{dB}(\mathrm{A})$ is the most commonly used measurement of community noise and is measured or calculated using the A-weighting filter to simulate the frequency response of the human ear. Figure 10 plots the linear weighting and A-weighting filter of combined noise level listed in the second to fourth column of Table 3. Originally, the A-weighting was designed to correspond to the response of the human ear to a pressure level of $72.9 \mathrm{~dB}(\mathrm{~A})$ at all frequencies. Since the human ear does not respond as strongly to low-frequency sounds, noise at low frequencies is generally less damaging or annoying than sound at high frequencies. The large negative weighting factor for low-frequency sound reflects this. Hence, A-weighting line has a lower noise level compared to linear weighting line for frequencies of $20 \mathrm{~Hz}$ to $800 \mathrm{~Hz}$ shown in Figure 10.

\section{Conclusion}

The overall noise calculated $15 \mathrm{~m}$ from a car is $85.1 \mathrm{~dB}(\mathrm{~L})$ from 20 to $1,000 \mathrm{~Hz}$ based on the linear energy weighting calculation and $72.9 \mathrm{~dB}(\mathrm{~A})$ based on the A-weighting calculation. $\mathrm{dB}(\mathrm{A})$ is the metric most commonly used to noise level when assessing impact on a community. Noise is measured or calculated using the A-weighting filter to simulate the frequency response of the human ear. This method of calculating noise is based solely on structural vibrations. The analysis excluded other noise sources on the train that may contribute to total noise, such as aerodynamic noise, interior noise, drive system noise, rail-wheel noise, and so on. Furthermore, calculations were based on just one carriage, though in a real world situation neighboring carriages would contribute to noise at the measurement point and increase total noise level. The overall noise level calculated by linear weighting thus will exceed $85 \mathrm{~dB}$. However, A-weighting noise is $72.9 \mathrm{~dB}(\mathrm{~A})$ and the overall noise considering all noise sources may still be below $85 \mathrm{~dB}$ at $15 \mathrm{~m}$ from a passing train.

\section{References}

[1] B. M. Ross and T. Wolde, "Noise from traffic as a worldwide policy problem," Noise Control Engineering Journal, vol. 49, no. 4, pp. 159-161, 2001.

[2] R. D. Stefano and B. Morri, "A statistical model for predicting road traffic noise based on poisson type traffic flow," Noise Control Engineering Journal, vol. 49, no. 3, pp. 137-143, 2001.

[3] C. M. Steele, "Critical review of some traffic noise prediction models," Applied Acoustics, vol. 62, no. 3, pp. 271-287, 2001.

[4] B. Li, S. Tao, R. W. Dawson, J. Cao, and K. Lam, "A GIS based road traffic noise prediction model," Applied Acoustics, vol. 63, no. 6, pp. 679-691, 2002.

[5] L. C. E. den Boer and A. A. Schroten, "Traffic noise reduction in Europe, solution for environment," Report on Economy and Technology, 2007.

[6] B. Li, S. Tao, and R. W. Dawson, "Evaluation and analysis of traffic noise from the main urban roads in Beijing," Applied Acoustics, vol. 63, no. 10, pp. 1137-1142, 2002.

[7] Ö. Gündoğdu, M. Gökdağ, and F. Yüksel, "A traffic noise prediction method based on vehicle composition using genetic algorithms," Applied Acoustics, vol. 66, no. 7, pp. 799-809, 2005.

[8] S.-Y. Hsia, S.-M. Chiu, and J.-W. Cheng, "Sound field analysis and simulation for fluid machines," Advances in Engineering Software, vol. 40, no. 1, pp. 15-22, 2009. 


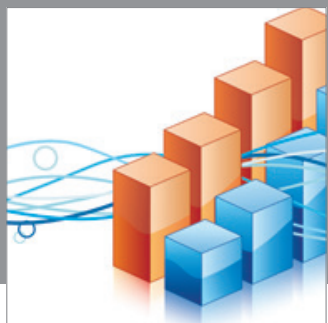

Advances in

Operations Research

mansans

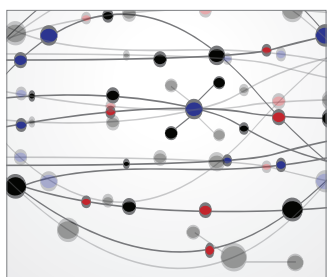

The Scientific World Journal
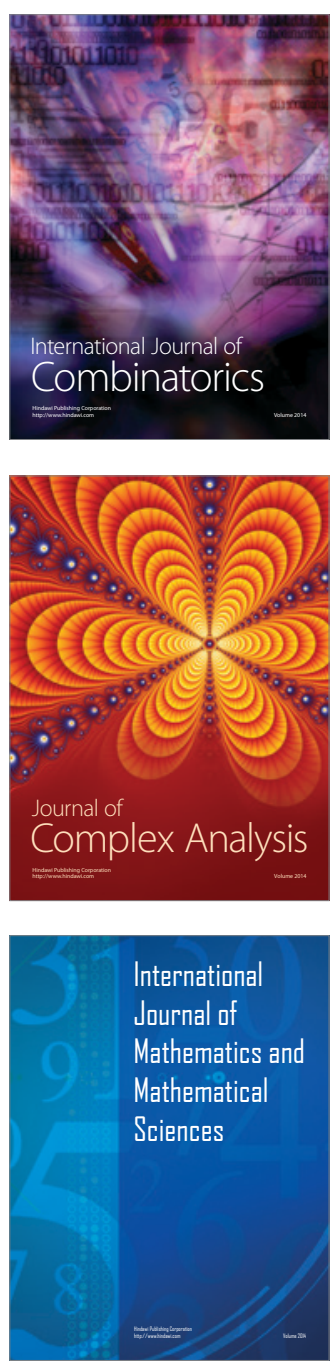
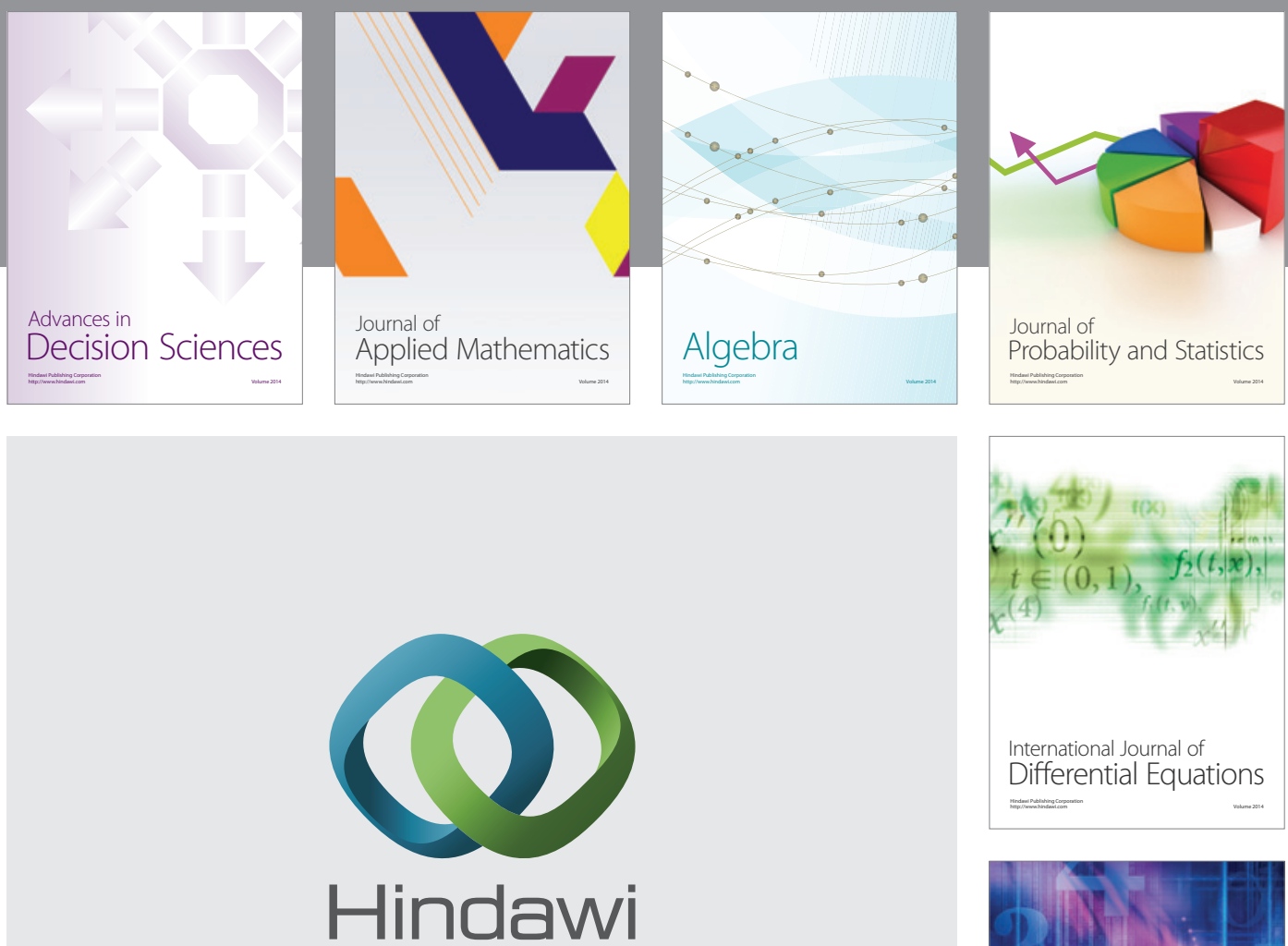

Submit your manuscripts at http://www.hindawi.com
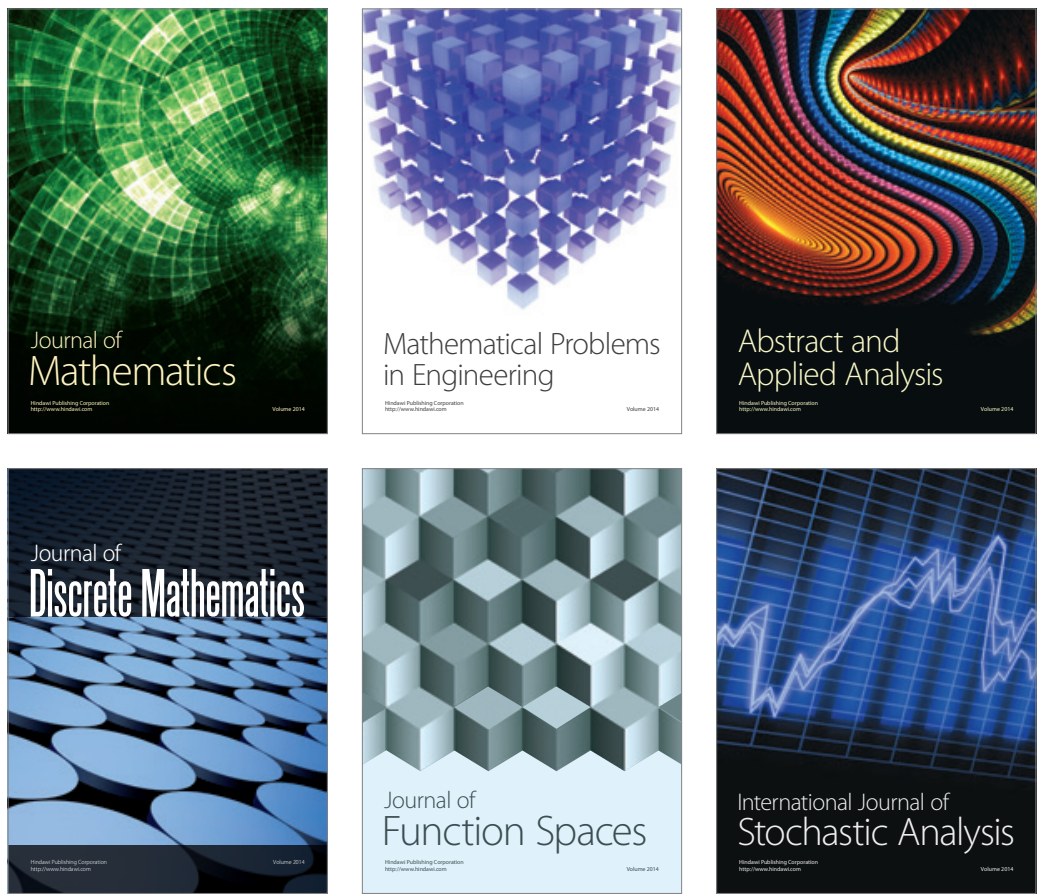

Journal of

Function Spaces

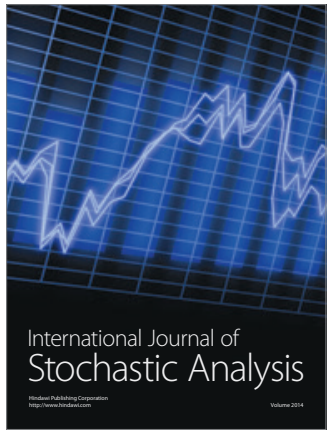

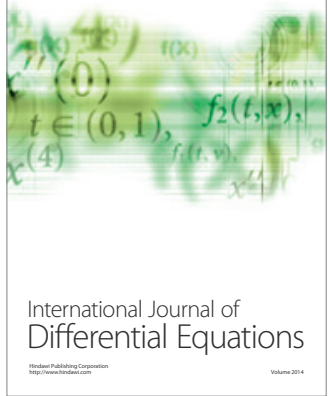
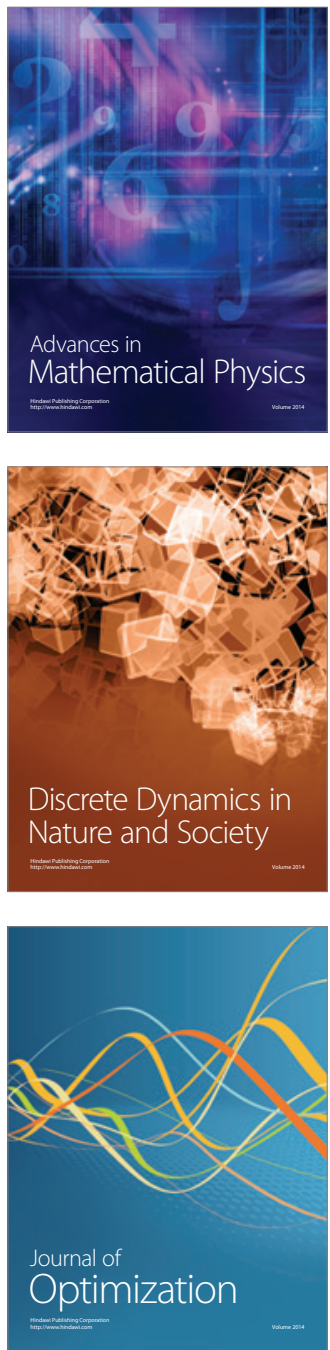